Vol 10, Issue 12, 2017

Online - 2455-3891
Print - 0974-2441

$\underline{\text { Research Article }}$

\title{
THE COMPARISON OF THE EFFECT BETWEEN ALGINATE-BASED RAFT-FORMING LIQUID AND ALGINATE LIQUID ON GASTROESOPHAGEAL REFLUX DISEASE AND GASTRIC ULCER IN RATS
}

\author{
HAKIM BANGUN ${ }^{1 *}$, ANAYANTI ARIANTO ${ }^{1}$, RIRIN ASTYA ${ }^{1}$, GONTAR A SIREGAR ${ }^{2}$ \\ ${ }^{1}$ Department of Pharmaceutical Technology, Faculty of Pharmacy, Nanomedicine Center, University of Sumatera Utara, Jl. Tri Dharma No. 5, \\ Kampus USU, Medan, Indonesia. ${ }^{2}$ Department of Internal Medicine, Faculty of Medicine, University of Sumatera Utara, Jl Dr. T. Mansyur \\ No. 5, Kampus USU, Medan, Indonesia. Email: hakimb17@yahoo.com \\ Received: 04 July 2017, Revised and Accepted: 16 August 2017
}

ABSTRACT

Objective: The objective of the study was to compare the effect between alginate (Alg)-based raft-forming and Alg liquid on healing gastroesophageal reflux disease (GERD) and gastric ulcer in rats.

Methods: Each of the 18 fasted rats was given $1 \mathrm{ml}$ acidified pepsin. Then, rats were divided into three groups. Each group consisted of six rats. Group 1 (negative control) was orally given $1 \mathrm{ml}$ distilled water, Group 2 was given $1 \mathrm{ml}$ Alg-based raft-forming liquid, and Group 3 was given $1 \mathrm{ml}$ Alg liquid. Then, the abdomen of rats was incised under anesthesia with ketamine, and then both their pylorus and the forestomach were ligated to form gastric reflux. After $4 \mathrm{hrs}$, all rats were killed with chloroform and their esophagus and stomach were examined macroscopically and microscopically (histopathology).

Results: On macroscopic observation, all of the Group 1 rats (negative control) showed esophageal lesions and gastric lesions. Four rats of Group 2 (given Alg-based raft-forming) showed no esophageal lesion and two more rats showed a slight lesion, but all of the tested rats showed gastric lesions. All of the rats of the Group 3 (given Alg liquid) showed esophageal lesions, but no gastric lesion on four rats and slight lesion on two rats. Microscopic observations showed that all of the Group 1 rats (negative control) showed esophageal erosion and gastric mucosa lesions. Rats of the Group 2 (given Alg-based raft-forming) showed almost no esophageal erosion, but all of them showed erosion of gastric mucosa. Rats of the Group 3 (given Alg liquid) showed esophageal erosion in all tested rats, but almost no gastric mucosa lesion.

Conclusion: Alg-base raft-forming liquid is more effective in healing of GERD than Alg liquid. However, Alg-liquid is more effective in healing of gastric ulcer than Alg-based raft-forming liquid.

Keywords: Alginate-based, Raft-forming, Alginate liquid, Gastroesophageal reflux disease, Gastric ulcer, Healing

(C) 2017 The Authors. Published by Innovare Academic Sciences Pvt Ltd. This is an open access article under the CC BY license (http://creativecommons. org/licenses/by/4. 0/) DOI: http://dx.doi.org/10.22159/ajpcr.2017.v10i12.21096

\section{INTRODUCTION}

Gastroesophageal reflux disease (GERD) is a retrograde flow of gastric or duodenal contents across the gastroesophageal junction into esophagus [1]. The predominant presenting symptom of reflux is burning chest pain (heartburn) resulting from recurrent mucosal injury, often worse at night, when lying supine, or after consumption of foods [2]. Medical treatment to relieve symptoms of GERD includes administering antacids, H2-receptor antagonists, and proton-pump inhibitor. In general, a drug used in dealing with GERD is antacids. Most antacids are available in a combination of aluminum and magnesium hydroxide in liquid dosage forms. The effect of antacids is short (1-2 hrs) [3], and conventional antacid preparations cannot work as physical barrier to reduce the GERD. One approach to cure GERD is with gastroretentive drug delivery system. Raft-forming systems have been received much attention for drug delivery for gastroretentive infection and disorders [4]. In this system when the alginate (Alg)-based raftforming liquid is orally administered, it immediately forms floating raft of Alg acid gel in the stomach. The floating gel is formed due to the gel trapped carbon dioxide $\left(\mathrm{CO}_{2}\right)$ which is yielded from the reaction of sodium bicarbonate and calcium carbonate of the preparation with hydrochloric acid from stomach. The precipitate alginic acid gel floats on the surface of the gastric contents such as a raft on water. Alg-based, raft-forming formulations have been used to treat reflux symptoms in infants and children and in the management of heartburn and reflux during pregnancy [5].
Alg can also be used for preparing gastroretentive and periodontal drug delivery systems [6-13]. Beside, Alg can be utilized in various biomedical applications including wound healing, cartilage repair, and bone and tissue regeneration [14]. Furthermore, in the previous study, we reported the healing effect of Alg liquid against $\mathrm{HCl}$-induced gastric mucosal lesions in rats [15]

Alg is a random copolymer of two units, $\beta$-D-mannuronic acid (M) and $\alpha$-L-guluronic acid $(\mathrm{G})$. Both of them are 1-4 linked and occur in regions or blocks of (M)n, (G)n, and (MG)n. Alg has been known to be non-toxic, cause no allergies, biodegradable, and biocompatible [16]

Based on the similarity of Alg-based raft-forming and Alg liquid that both preparation containing sodium Alg, so in this paper, it will be discussed the comparison of the effect of Alg-based, raft-forming liquid and Alg liquid on GERD and gastric ulcer.

\section{MATERIALS AND METHODS}

\section{Materials}

Sodium Alg 300-400 cP (Wako Pure Chemical Industries, Ltd., Japan). Canada balsam (Entellan), $\mathrm{HCl}$, sodium bicarbonate, pepsin, sodium hydroxide, chloroform, ethanol, liquid paraffin, xylol, xylene, hematoxylin, glycerin, and eosin were products of Merck. Formaldehyde, sucrose, calcium carbonate, nipagin, and nipasol were obtained from PT. Rudang. Ketamine injection was the product of Gordian Parmatama. 
Preparation of Alg-based raft-forming liquid

Alg-based raft-forming liquid was prepared according to the formula previously reported [17].

- $\mathrm{R} /$ sodium Alg - $1 \mathrm{~g}$

- Sodium bicarbonate $-2.67 \mathrm{~g}$

- Calcium carbonate - $1.6 \mathrm{~g}$

- Carbopol $934-0.65 \mathrm{~g}$

- Nipagin - $0.025 \mathrm{~g}$

- Simplex syrup - $25 \mathrm{~g}$

- Distilled water to $100 \mathrm{ml}$

Weighed each required ingredient. Sodium Alg was dissolved in a portion of distilled water, then allowed to stand for $24 \mathrm{hrs}$. Once coagulated, sodium Alg stirred until homogeneous, added calcium carbonate, and mixed until homogenous. Nipagin was dissolved in hot water. Sodium bicarbonate and carbopol were dissolved in distilled water. Mixed all ingredients and added simplex syrup and distilled water until $100 \mathrm{ml}$.

Preparation of Alg liquid

- $\mathrm{R} /$ sodium Alg - $1 \mathrm{~g}$

- Nipagin - $0.025 \mathrm{~g}$

- Simplex syrup - $20 \mathrm{~g}$

- Distilled water to $100 \mathrm{ml}$

Sodium Alg was dissolved in a portion of distilled water, then allowed to stand for $24 \mathrm{hrs}$ and was stirred until homogeneous. Nipagin was dissolved in hot water. Mixed all ingredients with the addition of simplex syrup and distilled water until $100 \mathrm{ml}$.

\section{Preparation of acidified pepsin}

A total of $0.1 \%(\mathrm{w} / \mathrm{v})$ pepsin was weighed, then mixed with $0.1 \mathrm{~N} \mathrm{HCl}$ solution until $100 \mathrm{ml}$

\section{Determination of floating lag time and floating time of Alg-based} raft

The floating time of Alg-based raft was determined by pouring $10 \mathrm{ml}$ of Alg-based raft-forming liquid into $100 \mathrm{ml}$ of simulated gastric fluid ( $0.1 \mathrm{~N} \mathrm{HCl}$ solution), and the time Alg-based raft-formed to float was recorded. The Alg raft was floated in surface of simulated gastric fluid. The floating time was the time that Alg-based raft was still remained floating in the surface of medium.

\section{Determination of preparation $\mathbf{p H}$}

The $\mathrm{pH}$ of floating Alg-based liquid and Alg liquid were determined using a pH meter (Hanna).

\section{Determination of preparation viscosity}

The viscosity of Alg-based raft-forming liquid and Alg liquid was determined using Brookfield viscometer.

\section{Treatment of GERD and gastric ulcer}

Animal experiments

Experiment animals used were healthy male rats Rattus norvegicus weighing 150-200 g that were kept in a cage, given standard pellet diets and tap water ad libitum. Ethical clearance for experimental protocol and handling the animals was obtained from the Animal Research Ethics Committees of Faculty of Mathematics and Natural Sciences, University of Sumatera Utara, before the beginning of the project work.

\section{Induction and healing of GERD and gastric ulcer}

The procedure of induction and treatment of GERD followed the previous method [18] with modification. Rats were fasted for $18 \mathrm{hrs}$ to get the esophagus was relatively clean of food. Rats were divided into three groups. Each group consisted of six animals and each rat was kept separately in a cage during the experiment.

- Group 1 (negative control): Rats were induced with $1 \mathrm{ml}$ of acidified pepsin solution; after $1 \mathrm{hr}$, rats were given $1 \mathrm{ml}$ distilled water, then they were anesthetized with $0.3 \mathrm{ml}$ ketamine injection intraperitoneally. Then, the stomachs were open, parts of pylorus and forestomachs were ligated. After that, the stomachs were sutured.
After $4 \mathrm{hrs}$, the rats were killed using chloroform, then the esophagus and stomachs were examined macroscopically and microscopically (histopathology) with hematoxylin staining

- Group 2: Rats were induced with $1 \mathrm{ml}$ acidified pepsin solution; after $1 \mathrm{hr}$, they were given $1 \mathrm{ml}$ Alg-based, raft-forming liquid. Then, the experiment was continued as conducted in Group 1

- Group 3: Rats were induced with $1 \mathrm{ml}$ acidified pepsin solution; after $1 \mathrm{hr}$, they were given $1 \mathrm{ml}$ Alg-liquid liquid. Then, the experiment was continued as conducted in Group 1.

\section{RESULTS AND DISCUSSIONS}

\section{Floating lag time and floating time of Alg-based raft}

When the Alg-based, raft-forming liquid was poured to simulate gastric fluid ( $\mathrm{pH}$ 1.2), the floated Alg-based raft was formed immediately (after 3 seconds), as shown in Fig. 1. In the medium of simulated gastric fluid, sodium Alg was immediately converted to insoluble alginic acid gel. The floated alginic acid gel on the surface of preparation was called "Alg based raft" [5]. The floating Alg-based raft was due to the presence of $\mathrm{CO}_{2}$ in the preparation as a result of the reaction of sodium bicarbonate and calcium carbonate from the preparation with $\mathrm{HCl}$ from simulated gastric fluid. This Alg-based raft floated on liquid content of the gastric due to low density and due to the formation of $\mathrm{CO}_{2}$. In unstirred condition, the Alg-based raft remained floated during 60 hrs as shown in Fig. 1. Therefore, in unstirred condition, the floating time was $60 \mathrm{hrs}$.

\section{$\mathrm{pH}$ of the Alg-based raft-forming preparation}

The average obtained $\mathrm{pH}$ of Alg-based raft-forming liquid obtained was $9(\mathrm{n}=3)$. This shows that the liquid Alg-based raft-forming as floating liquid dosage is alkaline. The $\mathrm{pH}$ of Alg liquid obtained was 6 .

pH of Alg-based raft-forming liquid after mixing with simulated gastric fluid

When $10 \mathrm{ml}$ of Alg-based raft-forming liquid was poured into $30 \mathrm{ml}$ of simulated gastric fluid ( $\mathrm{pH} 1.2$ ), the obtained $\mathrm{pH}$ was 5.8 , and when it was poured into $50 \mathrm{ml}$ of simulated gastric fluid, the obtained $\mathrm{pH}$ was 5.6. It indicates the Alg-based raft-forming liquid neutralized the simulated gastric fluid.

Viscosity of Alg-based raft-forming liquid

Viscosity Alg-based raft-forming was $15 \mathrm{cP}(\mathrm{n}=3)$, and the obtained viscosity of Alg liquid was $150 \mathrm{cP}$

The comparison of healing effect between Alg-based raft-forming liquid and Alg liquid on GERD

Macroscopic observation of rats' esophagus

The reflux causes the stomach contents flow to the esophagus and the stomach contents contact to the surface of esophagus. The severity of reflux was induced by double ligation of the pylorus and forestomach
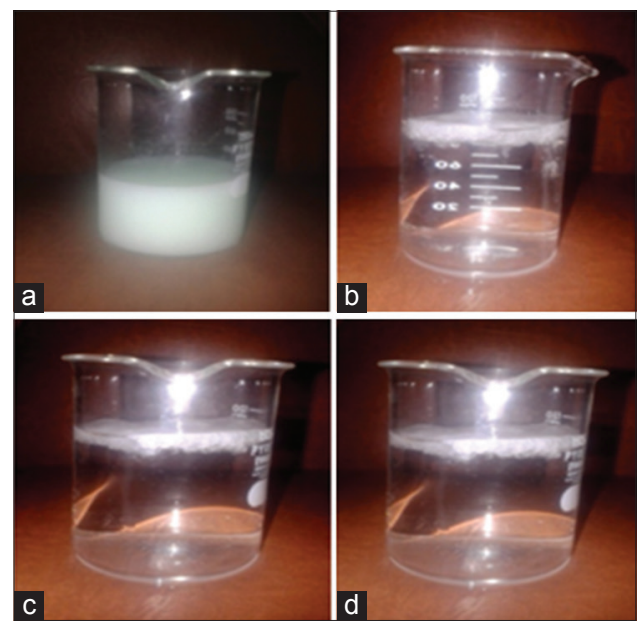

Fig. 1: Floating lag time and floating time of alginate-based raft, (a) Initial, (b) 3 seconds, (c) 24 hrs, (d) $60 \mathrm{hrs}$ 
of rats [18]. However, in this experiment, the esophagitis of the rat was not obtained by only the ligation of pylorus and forestomach. Therefore, $1 \mathrm{ml}$ acidified pepsin was orally administered to the rats before ligating of pylorus and forestomach to induce the esophagitis. After the reflux, the esophagitis is obtained as shown in Fig. 2a. The administration of rats with acidified pepsin before ligating caused the esophagitis and gastric ulcer.

The comparison of rats' esophagus which received only distilled water, Alg-based raft-forming liquid, and Alg liquid is shown in Fig. 2. The rats that received distilled water (Group 1) show a black color in almost of the esophagus. It is caused by stomach contents moved toward the esophagus and acidified pepsin induced the esophagus so caused the esophageal lesions and inflammation. Inflammation is characterized by the swelling of the esophagus that looks larger than normal esophagus. On the other hand, the esophagus of rats of Group 2 that received Algbased raft-forming liquid four of six rats that received Alg-base raftforming liquid showed no lesion, in other two rats, there were slight lesions of esophagus as shown in Fig. 2b. Rats of Group 3 that received Alg liquid, all of the six tested rats showed lesion with black color on their esophagus as shown in Fig. 2c.

In Table 1, it can be seen that in rats of Group 1 (negative control and given distilled water), the average area of esophagus was $217.17 \pm 28.39$ $\mathrm{mm}^{2}$; in rats of Group 2 (given Alg-based raft-forming), the average lesion of esophagus was much reduced to $6.33 \pm 1.41 \mathrm{~mm}^{2}$. In rats of Group 3 (given Alg liquid), the average esophagus lesion area was $199.53 \pm 27.72 \mathrm{~mm}^{2}$. This lesion area is not significantly different with lesion area of rats of Group 1.

In the presence of gastric acid, Alg acid was precipitated forming a gelatinous Alg acid gel. Alg-based raft-forming formulation contains sodium bicarbonate and calcium carbonate. In the presence of gastric acid, the carbonate was converted to $\mathrm{CO}_{2}$ which entrapped within the precipitated Alg acid gel so that it converting into a foam which floated on the surface of the gastric contents such as a raft on water, as shown in Fig. 1. Several studies have demonstrated that the Alg raft can preferentially move into the esophagus in place, or ahead, of acidic gastric contents during episodes of gastroesophageal reflux; but some studies further suggest that the raft can act as a physical barrier to reduce reflux episodes [5]. Possible mechanisms of action proposed Alg-based, raft-forming formulations include: (i) preferential reflux of the Alg raft into the esophagus; (ii) coating of the esophagus by the Alg raft which could then act as a muco- or cytoprotectant; (iii) formation of a physical barrier to prevent gastroesophageal reflux; and/or (iv) a combination of these effects [5].

In this study, the effect of Alg-based raft-forming was thought due to the suppression of gastric reflux due to the physical barrier by Alg raft as reported previously [17]. In the case of Alg liquid, although it contained Alg, it could not suppress the gastric reflux because the Alg in Alg liquid did not float in the stomach.

\section{Microscopic observation of rats' esophagus}

The comparison of the effect between Alg-based raft-forming, Alg liquid, and without treatment (given distilled water) based on the microscopic observation is shown in Fig. 3. Rats that receive distilled water show

Table 1: Comparison of the area of esophageal lesions in rat $\left(\mathrm{mm}^{2}\right)$

\begin{tabular}{llll}
\hline Rat & \multicolumn{2}{l}{ Area of lesion $\left(\mathbf{m m}^{\mathbf{2}}\right)$} & \\
\cline { 2 - 4 } & Distilled water & $\begin{array}{l}\text { Alg-based raft-forming } \\
\text { liquid }\end{array}$ & Alg liquid \\
\hline 1 & 181.00 & 20.00 & 208.25 \\
2 & 249.28 & 0 & 198.25 \\
3 & 190.35 & 18.00 & 242.82 \\
4 & 220.84 & 0 & 160.00 \\
5 & 247.95 & 0 & 205.53 \\
6 & 213.61 & 0 & 182.38 \\
Mean & $217.17 \pm 28.39$ & $6.33 \pm 1.41$ & $199.53 \pm 27.72$ \\
\hline
\end{tabular}

Alg: Alginate
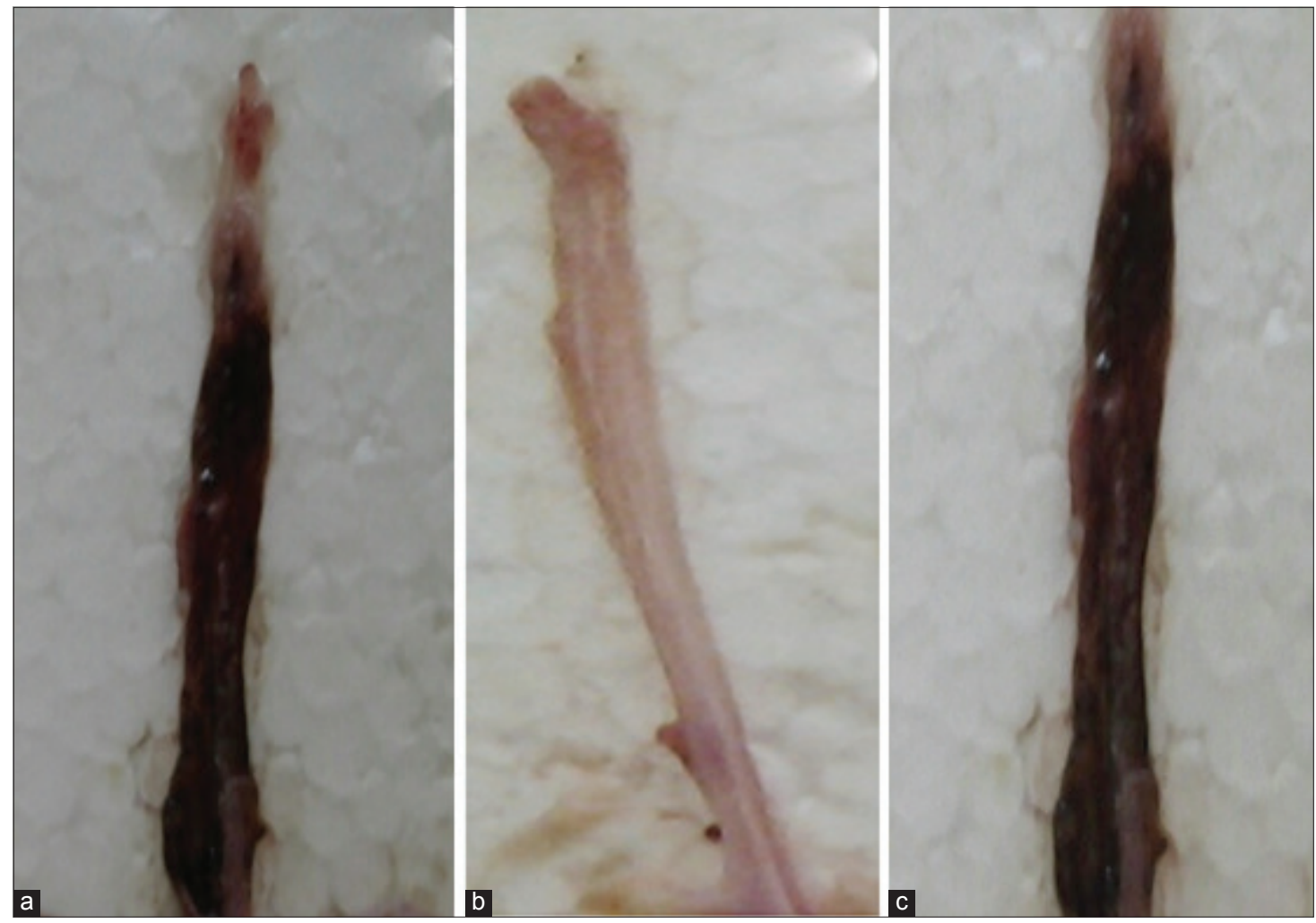

Fig. 2: Macroscopic of rats esophagus after induction. (a) Group 1 (negative control, given distilled water). (b) Group 2 (given alginate [Alg]-based raft-forming liquid). (c) Group 3 (given Alg liquid) 


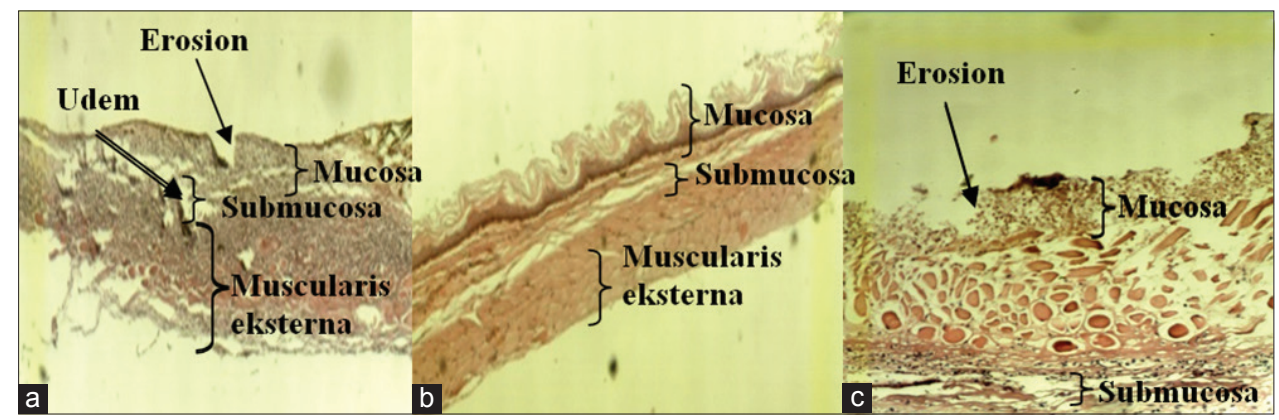

Fig. 3: Microscopic of esophageal tissue of rats with hematoxylin staining. (a) Group 1 (negative control, given distilled water), (b) Group 2 (given alginate [Alg]-based raft-forming), (c) Group 3 (given Alg liquid)
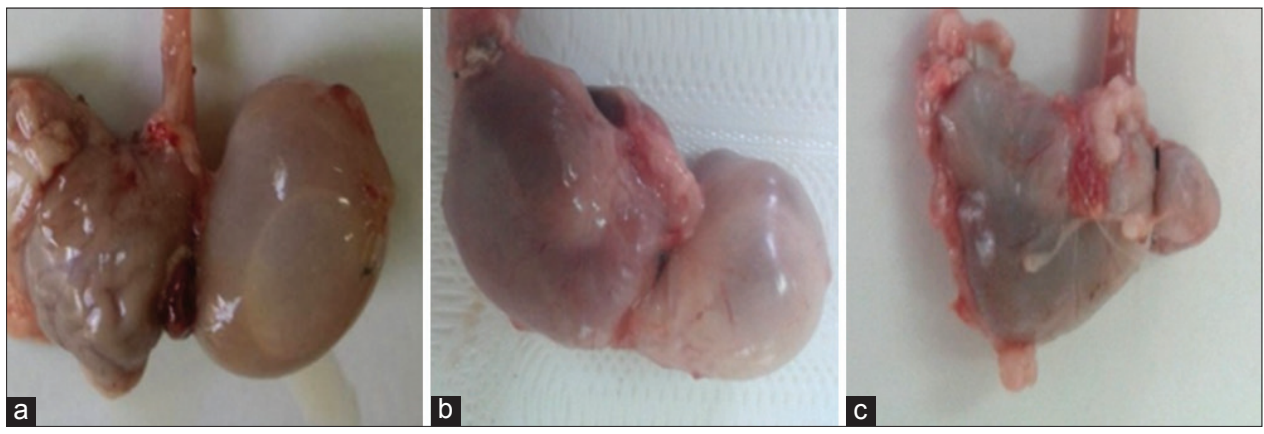

Fig. 4: Stomach of rats after induction. (a) Group 1 (negative control, given distilled water), (b) Group 2 (given alginate-based raftforming), (c) Group 3 (given alginate liquid)

Table 2: Comparison of the gastric lesion number in rats

\begin{tabular}{llll}
\hline Rat & Number of gastric lesion & & \\
\cline { 2 - 4 } & $\begin{array}{l}\text { Rats Group 1 (negative control, given } \\
\text { distilled water) }\end{array}$ & $\begin{array}{l}\text { Rats Group 2 (given Alg-based raft-forming } \\
\text { liquid) }\end{array}$ & Rats Group 3 (given Alg liquid) \\
\hline 1 & 15 & 0 & 2 \\
2 & 8 & 5 & 1 \\
3 & 12 & 5 & 0 \\
4 & 9 & 4 & 0 \\
5 & 5 & 3 & 0 \\
6 & 8 & 0 & 0 \\
Mean & $9.5 \pm 3.5$ & $2.8 \pm 2.3$ & $0.5 \pm 0.8$ \\
\hline
\end{tabular}

Alg: Alginate

Table 3: Comparison of the rat gastric lesion area $\left(\mathrm{mm}^{2}\right)$

\begin{tabular}{llll}
\hline Rat & \multicolumn{2}{l}{ Lesion area $\left(\mathbf{m m}^{\mathbf{2}}\right)$} & \\
\cline { 2 - 4 } & $\begin{array}{l}\text { Rats Group 1 (negative control, given } \\
\text { distilled water) }\end{array}$ & $\begin{array}{l}\text { Rats Group 2 (given Alg-based raft-forming } \\
\text { liquid) }\end{array}$ & Rats Group 3 (given Alg-liquid) \\
\hline 1 & 3.0 & 0 & 1.6 \\
2 & 1.0 & 1.0 & 1.5 \\
3 & 6.0 & 1.9 & 0 \\
4 & 1.5 & 1.5 & 0 \\
5 & 1.0 & 1.0 & 0 \\
6 & 2.1 & 0 & $0.5 \pm 0.8$ \\
Mean & $2.4 \pm 1.9$ & $0.9 \pm 0.7$ & 0.7 \\
\hline
\end{tabular}

Alg: Alginate

the erosion of the mucosal lining of the esophagus as shown in Fig. 3a. However, rats that receive Alg-based raft-forming shows the good cohesion between mucosal cells and no damage of mucosa as shown in Fig. 3b. Rats that receive Alg-liquid shows the damage of mucosa, where the cohesion between mucosal cells is still not good as shown in Fig. 3c. Based on this microscopic observation, it can be concluded that the Alg-based raft-forming prevents the formation of the GERD, but Alg liquid is not effective to heal the GERD.
The comparison of healing effect between Alg-based raft-forming liquid and Alg liquid on gastric ulcer Observation of stomachs morphology

In this experiment, after induction with acidified pepsin solution, beside, esophagus of the rats' stomach was also observed. The induction caused the swelling of rats' stomach due to the accumulation of gas as shown in Fig. 4a. This gas is thought come from the product of 

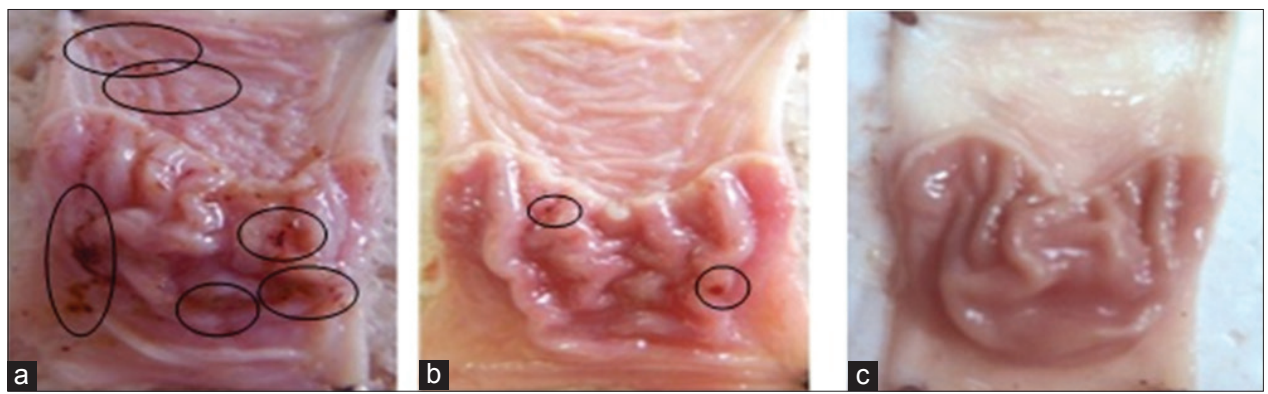

Fig. 5: Rats gastric mucosa. (a) Group 1 (negative control and given distilled water), (b) Group 2 (given Alg-based raft-forming liquid), (c) Group 3 (given Alg-liquid)
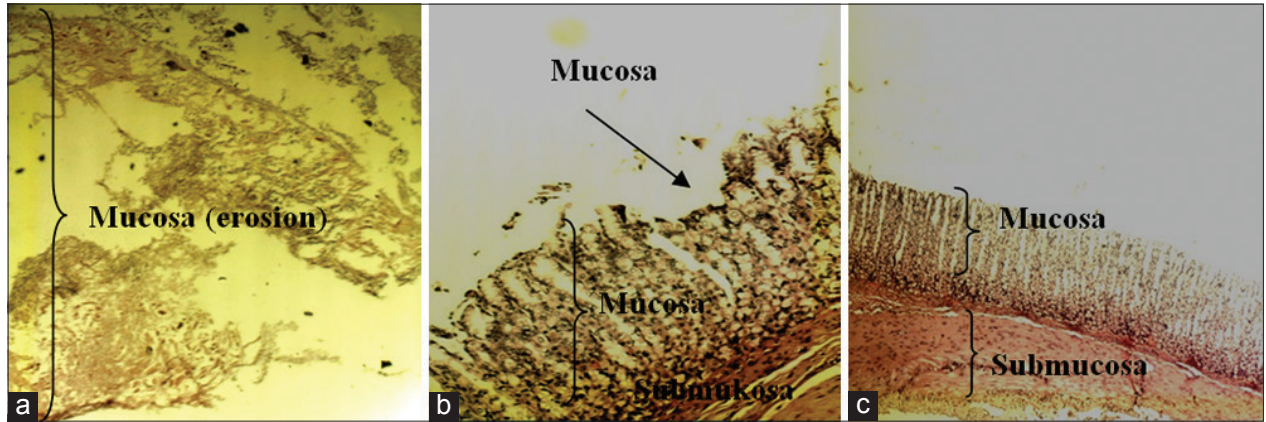

Fig. 6: Microscopic of rats gastric mucosa with hematoxylin staining. (a) Group 1 (negative control, given distilled water), (b) Group 2 (given alginate [Alg]-raft forming), and (c) Group 3 (given Alg liquid)

the reaction between hydrochloric acid and sodium bicarbonate that is secreted from the surface of epithelial cells of mucosa. Hydrochloric acid and pepsin caused damaged of mucosa barrier and then cause the back diffusion of hydrochloric acid and lead to the destruction of the capillary and venous blood so that resulting stomach bleeding [19]. Fig. 4 shows the comparison of rats' stomach that received distilled water, Alg-based raft-forming, and Alg liquid. The stomach of rats that received distilled water swelled (arrow) and the degree of swelling was higher than that received Alg-based raft-forming liquid as shown in Fig. $4 \mathrm{a}$ and $\mathrm{b}$. On the other hand, rats that given Alg liquid showed the lowest of swelling as shown in Fig. 4c.

\section{Macroscopic observation of rats stomach}

Rats that received only distilled water (negative control), beside the swelling of stomachs, the gastric mucosa lesions were formed as shown in Fig. 5a. All of the rats that received only distilled water got gastric lesions, the average number of lesion was $9.5 \pm 3.5$ (Table 2) and the average lesion area was $2.4 \pm 1.9 \mathrm{~mm}$ (Table 3). For rats that received Alg-based raft-forming liquid, two of the 6 rats tested had no lesion (Fig. 5b), the average number of lesion was $2.8 \pm 2.3$, and the average lesion area was $2.8 \pm 2.3 \mathrm{~mm}$. While rats that received Alg liquid, four of the six tested rats had no lesion (Fig. 5c), the average number of lesion was $0.5 \pm 0.8$, and the average lesion area was $0.5 \pm 0.8 \mathrm{~mm}$. These results show that Alg liquid is more effective in treating gastric ulcer than Alg-based raft-forming liquid.

\section{Microscopic observation of rats' stomach}

The microscopic observation of rats' stomach is shown in Fig. 6. In the rats that were given distilled water (negative control) (Fig. 6a) and Alg-based raft-forming (Fig. 6b) show the cohesion between the cells are damaged, and the erosion of the lining of the stomach mucosa, but the damage of stomach mucosa is more serious in the negative control group. Meanwhile, in rats that received Alg liquid show good gastric mucous layer and no erosion (Fig. 6c). Therefore, based on the results of microscopic (histopathology) observation, it can be concluded that Alg liquid is more effective than Alg-based raft-forming for the treatment of gastric ulcer that caused by exposure to acid and pepsin to mucosa of stomachs.
In the stomach, in the presence of gastric acid, sodium Alg was changed to alginic acid gel. This alginic acid gel has mucoadhesive properties [20]. Therefore, alginic acid adhered to the surface of gastric mucosa and acted as a mucoprotective agent by providing a physical barrier to hydrochloric acid and pepsin to contact the gastric mucosa, thereby improving the lesion or ulcer-healing [21]. Besides, Alg increases the hexosamine levels, which are glycoprotein constituting of gastric mucus [21].

\section{CONCLUSIONS}

Alg-based raft-forming liquid form Alg acid gel which float on the surface of gastric contents such as raft in water and it suppresses the gastric reflux. Alg liquid although it contains Alg, it could not form float Alg acid gel in the stomach, thereby it could not suppress the gastric reflux. Therefore, Alg-based raft-forming liquid is effective in healing GERD, but Alg liquid is not effective. Alg-based raft-forming is also effective in healing gastric ulcer, but it is less effective than Alg liquid.

\section{REFERENCES}

1. APhA (American Pharmaceutical Association). Handbook of Nonprescription Drugs. $8^{\text {th }}$ ed. Washington, DC: American Pharmaceutical Association; 1986. p. 22.

2. McPhee JS, Ganong FW. Pathophysiology of Disease: An Introduction to Clinical Medicine. $5^{\text {th }}$ ed. Ch. 13. USA: The McGraw-Hill; 2006

3. Katzung GB, Trevor JA. Basic and Clinical Pharmacology. $13^{\text {th }}$ ed. New York: McGraw-Hill; 2015. p. 1429.

4. Nasa P, Mahant S, Sharma D. Floating system: A novel approach towards gastroretentive drug delivery system. Int J Pharm Pharm Sci 2010;2(3):2-7.

5. Mandel KG, Daggy BP, Brodie DA, Jacoby HI. Review article: Alginate-raft formulations in the treatment of heartburn and acid reflux. Aliment Pharmacol Ther 2000;14(6):669-90.

6. Aryana, Sinurat D, Revina I, Bangun H. Formulation and in vitro evaluation of alginate based metronidazole periodontal gel. Asian J Pharm Clin Res 2014;7(1):223-7.

7. Adlin N, Bangun H, Karsono. Preparation and evaluation of floatingmucoadhesive alginate beads as gastroretentive drug delivery system of antacids. Int J PharmTech Res 2016;9(5):212-22.

8. Mariadi, Bangun H, Karsono. Formulation and in vitro evaluation of 
gastroretentive drug delivery system of antacids using alginate-chitosan films. Int J PharmTech Res 2015;8(9):1-12.

9. Kulkarni P, Keshavayya J. Chitosan-sodium alginate biodegradable interpenetrating polymer network (IPN) for delivery of ofloxacin hydrochloride. Int Pharm Pharm Sci 2010;2(2):77-82.

10. Arianto A. Antiulcer effect of gastroretentive spherical matrices of alginate-chitosan containing ranitidine HCL. Int J PharmTech Res 2016;9(5):342-52

11. Arianto A, Bangun H, Yohana A, Silalahi J. Floating gastroretentive of amoxicillin using hard alginate capsules and antibacterial activities. Asian J Pharm Clin Res 2017;10(5):413-9.

12. Hasan JM, Kamal AB. Formulation and evaluation of ranitidine hydrochloride as floating in situ gel. Int $\mathrm{J}$ Pharm Pharm Sci 2014;6 Suppl 2:401-15.

13. Morsi N, Ghorab D, Refai H, Teba H. Preparation and evaluation of alginate/chitosan nanodispersion for ocular delivery. Int J Pharm Pharm Sci 2015;7(7):234-40

14. Sun J, Huaping T. Alginate-based biomaterial for regenerative medicine applications. J Mater 2013;6:1285-309.

15. Arianto A, Bangun $H$. Healing effect of alginate liquid against
HCL-induced gastric mucosal lesion in rats. Int $\mathrm{J}$ PharmTech Res 2016;9(3):287-96

16. Smidsrød O, Skjåk-Braek G. Alginate as immobilization matrix for cells. Trends Biotechnol 1990;8(3):71-8.

17. Withington R. Pharmaceutical Compositions for Use in the Suppression of Gastric Reflux. 1979; United States Patent. p. 1-5.

18. Takeuchi K, Nagahama K. Animal model of acid-reflux esophagitis: Pathogenic roles of acid/pepsin, prostaglandins, and amino acids. Biomed Res Int 2014;2014:532594.

19. Price SA, Wilson LM. Pathophysiology: Clinical Concepts of Disease Processes. $3^{\text {rd }}$ ed. New York: McGraw-Hill Book Company; 1986. p. 242-58.

20. Arianto A, Bangun H, Harahap U, Ilyas S. The comparison of swelling, mucoadhesive, and release of ranitidine from spherical matrices of alginate, chitosan, and calcium alginate-chitosan. Int J PharmTech Res 2014;6(7):2054-63.

21. Daigo K, Wada Y, Yamada C, Yamaji M, Okuda S, Okada M, et al. Pharmacological studies of sodium alginate. I. Protective effects of sodium alginate on mucous membranes of uppergastrointestinaal tract. Yakugaku Zasshi 1981;101(5):452-7. 